\title{
Montana State University Research Data Census Instrument, Version 2
}

\section{Authors: Jason A. Clark, Pol Llovet, Sara Mannheimer, Jerry Sheehan}

Montana State University developed the Research Data Census (RDC) to engage our local research community in an interactive dialogue about their data. The research team was particularly interested in learning more about the following issues at Montana State: the size of research data; data storage needs; data sharing and publication behaviors; and interest in existing services that assist with the curation. Version 1 of the RDC (http://doi.org/10.15788/m2h59m) was distributed in January 2015. Version 2 was distributed in spring 2016.

Version: v2

Date uploaded: October 2016

DOI: http://doi.org/10.15788/M2K01G

Suggested Citation: Clark JA, Llovet P, Mannheimer S, Sheehan J (2016) Montana State University Research Data Census Instrument, Version 2. Montana State University ScholarWorks. http://doi.org/10.15788/M2K01G 


\section{MSU Data Census 2016}

Thank you for participating in the 2016 Data Census! Participation in this survey is voluntary. You may opt out of any question, and you may stop the survey at any time.

Name:

Email Address: 
What department(s) and/or institute(s) are you affiliated with? Hold down the "Control" (Windows) or "Command" (Mac) key to select multiple entries.

a Agricultural Economics \& Economics (4)

- Agricultural Education (5)

- Agricultural Experiment Station (6)

- Alderson Entrepreneurship Program (7)

- American Indian Research Opportunities (8)

American Studies (9)

Animal \& Range Sciences (10)

a Architecture (11)

art (12)

Bracken Center (13)

- Burns Technology Center (14)

口 Cell Biology \& Neuroscience (15)

a Center for Biofilm Engineering (16)

口 Center for Biofilm Engineering (17)

- Center for Computational Biology (18)

- Center for Native Health Partnerships (19)

a Chemical \& Biological Engineering (20)

- Chemistry \& Biochemistry (21)

C Civil Engineering (22)

- College of Agriculture - Research Centers (23)

- Computer Science (24)

- Division of Health Sciences (25)

Earth Sciences (26)

- Ecology (27)

Education (28)

- Electrical \& Computer Engineering (29)

English (30)

Extended University (31)

口 Film \& Photography (32)

- Gallatin College - Developmental Education (33)

口 Gallatin College - Dual Enrollment (34)

- Gallatin College - General Education \& Transfer (35)

- Gallatin College - Workforce Degree Programs (36)

- Graduate Departments and Degrees (37)

- Health \& Human Development (38)

] Health Professions Advising (39)

- History \& Philosophy (40)

प Honors College (41)

- Intercollege Programs for Science Education (42)

口 International Programs (43)

- JJCBE Center for Entrepreneurship (44)

- Land Resources \& Environmental Sciences (45) 
- Lewis \& Clark Troops to Teachers (46)

口 Liberal Studies (47)

口 Library (48)

- Local Government Center (49)

- Master of Professional Accountancy (50)

- Master of Science in Science Education (51)

a Mathematical Sciences (52)

acNair Scholars Program (53)

- Mechanical \& Industrial Engineering (54)

- Microbiology \& Immunology (55)

Military Aerospace Studies (Air Force ROTC) (56)

Military Science (Army ROTC) (57)

- Modern Languages \& Literatures (58)

- Molecular Biosciences Program (59)

a Montana Area Health Education Center (60)

a Montana INBRE (61)

a Montana Institute on Ecosystems (62)

- Montana Manufacturing and Extension Center (63)

- Montana NASA EPSCoR (64)

- Montana Office of Rural Health (65)

- Montana Space Grant Consortium (66)

- Montana University System Water Center (67)

a Museum of the Rockies (68)

a Music (69)

- Native American Studies (70)

ㄱursing (71)

- Office of Continuing Education (72)

a OpTec (73)

a Physics (74)

- Planning \& Analysis (75)

- Plant Sciences \& Plant Pathology (76)

- Political Science (77)

a Psychology (78)

- Research Computing Group (79)

- Sociology and Anthropology (80)

- Spectrum Lab (81)

口 Thermal Biology Institute (82)

口 Undergraduate Scholars Program (83)

口 University Studies (84)

- Western Transportation Institute (85)

- Wheeler Center (86)

- Wind Applications Center (87)

- WWAMI Medical Education Program (88)

O Other (3) 
If you chose "other," please specify

What is your role in research? (Check all that apply)

口 Undergraduate student (1)

G Graduate student (7)

口 Postdoc (2)

S Staff (3)

G Faculty (4)

- Administrator (5)

Other (please specify) (6) 


\section{Research Data Characteristics}

What is the nature of your scholarly work?

- Qualitative data collection and analysis (4)

Q Quantitative data collection and analysis (5)

C Creative work (6)

Teaching $(7)$

$\square$ Other (please specify) (8)

Please estimate the percentage of each of the types of data listed below that you generate in your research. (Selections must total 100.) Spreadsheets (1) Text (2) Audio (3) Video (4) Images (5) GIS (6) Timeseries (7) Streaming sensor data (8) Other (please specify) (9) Other (please specify) (10)

Is your research data digital (e.g. created and stored on a computer), physical (e.g. paper, specimens), or a mixture of both?

O Primarily digital (1)

O Primarily physical (2)

Mixture of digital and physical, but mostly digital (3)

Mixture of digital and physical, but mostly physical (5)

An even mix of digital and physical (6)

Other (please specify) (4)

Please estimate the approximate total size of your research data.

Exact amount in MBs, GBs, or TBs (please be as specific as possible): (12)

Less than $10 \mathrm{~GB}$ (Fits on a USB stick) (1)

O Between 10 and 100 GB (Fits on my computer's hard drive) (2)

O Between 100 and 1 TB (Fits on an external hard drive) (3)

O Between 1TB and 100TB (Too big for an external hard drive) (9)

O More than 100TB (10)

O I'm still not sure (7)

Additional comments about the characteristics of your research data: 


\section{Data Storage}

Where do you store your current research data? (Check all that apply)

As paper copies or in notebooks (1)

On my office computer or a lab computer (2)

- On an external drive to my computer (3)

On an MSU resource (please specify) (4)

On a cloud service (5)

Off campus (please specify) (6)

$\square$ Other (please specify (7)

If you store your research data on a cloud service, which do you use?

Google Drive (1)

口 Box - MSU institutional account (2)

Box - Personal account (6)

Dropbox (3)

- OneDrive (4)

Other (please specify) (5)

Is your current research data backed up or duplicated anywhere?

Yes, all of it (2)

Yes, some of it (6)

No, none of it (5)

If No, none of it Is Selected, Then Skip To Where do you store data related to yo...

Where is your current data backed up or duplicated? (Check all that apply)

On my office computer or a lab computer (2)

$\square$ On an external drive to my computer (3)

On an MSU resource (please specify) (4)

On a cloud service (5)

Off campus (please specify) (6)

O Other (please specify) (7)

Answer If Where is your current data backed up or duplicated? (Check all that apply) On a cloud service Is Selected

If you use a cloud service to backup or duplicate your research data, which do you use?

Google Drive (1)

Box (2)

Dropbox (3)

$\square$ OneDrive (4)

O Other (please specify) (5) 
Is there a cost for this backup or duplication?

O Yes (1)

No (2)

Answer If Is there a cost for this backup/duplication? Yes Is Selected

What is the cost?

Where do you store data related to your prior research? (Check all that apply)

In a public repository (e.g. MSU ScholarWorks, Dryad, Figshare) (3)

On my office computer or a lab computer (13)

- On an external drive to my computer (4)

On an MSU resource (please specify) (6)

On a cloud service (7)

Off campus (please specify) (5)

$\square$ Other (please specify) (12)

Do you have a need for supplementary storage for your scholarly work or research data?

O Yes (1)

No (2)

Answer If Do you have a need for additional long-term storage for your scholarly works or research data? Yes Is Selected

What initial size would be optimal for such storage?

O $1 \mathrm{~GB}(4)$

O $100 \mathrm{~GB}(5)$

O 500GB (6)

○ 1 TB (7)

O 10 TB (8)

Other (please specify) (9)

Answer If Do you have a need for additional long-term storage for your scholarly works/data?

Yes Is Selected

What would be the easiest way for you to access data in long-term storage?

- Mapped drive available from my personal computer desktop (5)

- Access via file transfer protocol (6)

Access via the web (7)

Access via a third party client software I would need to install on my personal computer (8)

No preference (9) 


\section{Data Sharing}

Do you share your data with off-campus collaborators?

O Yes (1)

No (2)

Answer If Do you share your data with off-campus collaborators? Yes Is Selected If you share your data with off-campus collaborators, where are they located? Please list the specific university, federal agency, research lab, etc.)

Do you download data from other sources or repositories for your research?

O Yes (1)

O No (2)

Answer If Do you download data from other sources or repositories for your research? Yes Is Selected

If you download data from other sources or repositories, please list the source or repository.

Do you share your data publicly?

O Yes, immediately (1)

Yes, after article is accepted for publication (5)

Yes, after academic publication (3)

Yes, after grant ends (2)

O No (4)

If No Is Selected, Then Skip To If you don't share your data publicly...

Where do you share your data publicly?

If you share your data publicly, how do you transfer the data to the sharing venue? (Check all that apply)

Email attachment (4)

$\square$ Globus (5)

Cloud service (6)

$\square$ Ship a physical hard drive (7)

Other (please specify) (8)

\section{Answer If Do you share your data publicly? No Is Selected}

If you don't share your data publicly, why not? (Check all that apply)

I I don't work collaboratively with my data (3)

Data is restricted or sensitive (4)

Data is too big (5)

$\square$ Other (please specify) (6) 
Answer If Do you share your data publicly? No Is Selected

Would you ever consider sharing data publicly? What factors would influence this decision?

Have you ever used our institutional data repository (MSU ScholarWorks) to publicly share data?

O Yes (1)

O No (2)

Answer If Have you ever used our institutional data repository (MSU ScholarWorks) to publicly share data? ... No Is Selected

Would you be interested in sharing data in MSU ScholarWorks?

O Yes (1)

O No (2)

Which infrastructure, tools, or services are important to your research data efforts? Please drag the items into the box on the right in order of importance.

Infrastructure, tools, or services in order of importance

Data transfer speed (4)

Open data publishing (5)

Cloud storage (6)

Core Facilities on campus (7)

Data collaboration tools (please specify) (8)

Data security (9)

Data management planning (10)

Other (please specify) (11)

Additional comments about data storage: 
Data Archiving Requirements

Do you have a funding source requirement to make data available online after your research?

O Yes (1)

O No (2)

If No Is Selected, Then Skip To Do the journals you publish with requ...

Please list the funding source(s).

Please describe the funder requirement.

Does the funding source provide monetary support to meet this requirement?

Y Yes, one-time (4)

Y Yes, ongoing (5)

No (3)

Do the journals you publish with require data publication?

O Yes (1)

No (2)

Are there any other requirements to make data available online after your initial publications?

Yes (please explain) (1)

O No (3)

Answer If Do you have any other requirements to make data available online after your initial publications? Yes (please explain) Is Selected Or Do the journals you publish with require data publication? Yes Is Selected

If you have requirements to make data available online after your initial publications, where do you make your data available?

Answer If Do the journals you publish with require data publication? Yes Is Selected Or Do you have any other requirements to make data available online after your initial publications? Yes

(please explain) Is Selected

For how long must the data be made available?

O 1 -5 years (1)

5-10 years (6)

For the long term (8)

O Other (10) 
Answer If Do the journals you publish with require data publication? Yes Is Selected Or Do you have any other requirements to make data available online after your initial publications? Yes (please explain) Is Selected

Are there any financial or community resources to support this data availability requirement? (please explain)

Additional comments about data archiving requirements: 
Institutional Data Storage Business Model

Which business model would you prefer for research data storage?

No-cost standard allocation of data storage, with additional fee-based option for expanded storage (4)

No-cost standard allocation of data storage, with additional storage for those who meet certain criteria (e.g. funded by an agency that requires archiving, part of a research lab) (5)

Fee-based data storage service (6)

Other (please specify) (7)

When applying for external grants, do you anticipate being able to allocate funds in your budget toward institutional data storage?

O Yes (1)

No (2)

Does our institutional Box account meet your research data storage needs?

O Yes (1)

No (2)

Answer If Does our institutional Box account meet your research data storage needs? No Is Selected

Why not?

Additional comments about an institutional data storage business model: 
Would you be interested in learning more about data infrastructure, services, and assistance available from MSU IT Center and Library?

O Yes (1)

No (2) 